\title{
Prevalence, psychological impact, and risk factors of erectile dysfunction in patients with Peyronie's disease: a retrospective analysis of 309 cases
}

This article was published in the following Dove Press journal:

Research and Reports in Urology

18 July 2016

Number of times this article has been viewed

\author{
Gianni Paulis 1,2 \\ Gennaro Romano 3 \\ Andrea Paulis ${ }^{4}$ \\ 'Department of Surgical Sciences, \\ Andrology Center, Regina \\ Apostolorum Hospital, Albano L., \\ Italy; ${ }^{2}$ Department of Uro-Andrology, \\ Peyronie's Disease Care Center, \\ Rome, Italy; ${ }^{3}$ Department of Urologic \\ Oncology, Section of Avellino, Italian \\ League Against Cancer, Avellino, Italy; \\ ${ }^{4}$ Section of Psycho-Sexology, \\ Peyronie's Disease Care Center, \\ Rome, Italy
}

\begin{abstract}
Peyronie's disease (PD) is a chronic inflammatory disease involving the tunica albuginea of the penis. Erectile dysfunction (ED) is a possible invalidating symptom of PD. The aim of this study was to evaluate the prevalence, psychological impact, and risk factors of ED in patients with PD. The study was conducted by carrying out a retrospective analysis of the clinical records of 309 patients with PD who visited our andrology clinic. All patients underwent the following tests: body mass index, common blood tests and hormone assays, questionnaire for erectile function assessment, dynamic penile color Doppler ultrasonography, imaging of the penis at maximum erection with photographic poses according to Kelâmi, psychosexual impact evaluation with PD Questionnaire (symptom bother score), evaluation of depression symptoms with the Patient Health Questionnaire-9, and evaluation of the intensity of penile pain with the pain intensity numeric rating scale. ED was observed in $37.5 \%$ of the cases. We divided the cases into two groups: group A (PD + ED), 116 cases, and group B (PD without ED), 193 cases. After multivariate analysis, we concluded that the following comorbidities are independent risk factors for ED: dyslipidemia, obesity, chronic prostatitis, benign prostatic hyperplasia, and autoimmune diseases. A depressive disorder was observed in $62.4 \%$, and it was more frequent in patients with PD + ED ( $91.37 \%$ versus $45.07 \%$ group B). Sexual bother was greater in group A compared with group B (9.7 versus 7.6). Intensities of depressive symptoms and sexual bother were significantly higher compared with cases with no curvature when the bend angle was $\geq 30^{\circ}$. Our study confirms that an integrated psychological support with medical treatment is needed in patients with PD.
\end{abstract}

Keywords: Peyronie's disease, erectile dysfunction, psychological distress, psychosocial impact, risk factors

\section{Introduction}

Peyronie's disease (PD) is a chronic inflammatory disease involving the tunica albuginea of the corpora cavernosa. Its prevalence varies in studies between $3.2 \%$ and $13 \%,{ }^{1-3}$ and it mostly affects men between 50 years and 60 years of age. Although the etiopathogenesis of the disease is still not completely clear, the currently leading theory links it to trauma (macrotrauma and microtrauma). ${ }^{4-9}$ It has been ascertained that genetic transmission of the disease may be possible; after all, the frequent likelihood of association of PD with Dupuytren's contracture and Paget's disease is well known. ${ }^{10-12}$ The course of PD can be divided into two stages. The initial acute inflammatory stage lasts $\sim 12-18$ months. ${ }^{13,14}$ In this phase, the disease progresses rapidly, causing the growth of plaque and penis deformation. The initial stage is followed by a chronic
Correspondence: Gianni Paulis

Peyronie's Disease Care Center, Via

Castefidardo 34, 00185

Rome, Italy

Tel +3906 428I 42II

Email paulisg@libero.it 
inflammatory stage, where stabilization of the disease is gradually reached. In this phase, curvature and penile plaque tend to stop progressing and growing, pain disappears, and the by now extensively fibrotic, calcified plaque can be easily felt on palpation. ${ }^{15}$ The progressive growth of penile plaque caused by excessive production of collagen leads to a gradual reduction in the elasticity of the tunica albuginea, resulting inevitably in a morphological variation of the penis (curvature, shortening, divots, hourglass deformity, etc). Besides the fairly frequent symptom of penile curvature (75\%-94\%), ${ }^{16,17}$ other possible symptoms include penile pain and erectile dysfunction (ED). Painful erection, typical of the first stages of the disease, may be present in a percentage that varies in the literature between $20 \%$ and $70 \% .^{17,18}$ In certain cases, penile pain may be present even at rest.

ED may be associated with $\mathrm{PD}$ in a percentage varying between $31.5 \%$ and $60.1 \%{ }^{16,19} \mathrm{ED}$ is one of the most invalidating symptoms of PD. It can have several causes, and in certain cases, the penile deformations themselves (excessive angle or shortening, etc) caused by the disease can make coitus very difficult or impossible. However, some authors have noted that, in certain cases, ED can precede the onset of PD (from $40.2 \%$ to $57.6 \%$ ). ${ }^{20-22}$ Incomplete erection would thus favor the occurrence of repeated microtrauma during intercourse, causing the subsequent onset of the disease in genetically predisposed males. ${ }^{16,21-24}$

Another cause of ED can be the penile plaque itself, which, if sufficiently large, may compress the cavernous artery system, occasionally causing evident divots or hourglass deformity of the penis. ${ }^{16-25}$

An analogous situation is present in the cases of "flail penis", where extensive fibrosis causes in its location an absence of erection; this condition occurs even distally, resulting in a "soft" penis beyond the normally rigid healthy tissue. ${ }^{17,26}$ The conviction that ED in the course of PD is caused by venous occlusive dysfunction is very widespread, ${ }^{27}$ but it is also possible that it may be caused by arterial insufficiency or a combination of the two, or simply by psychological issues. In 1993, Lopez and Jarow, ${ }^{27}$ after having performed a vascular study with dynamic penile Doppler ultrasound in 76 patients with ED associated with PD, found veno-occlusive dysfunction in $59 \%$ of cases and cavernous arterial insufficiency in $36 \%$ of cases.

However, other authors, after studying patients affected by ED associated with PD, obtained different results and they concluded that cavernous artery insufficiency (and not venous occlusive dysfunction) represents the major cause of ED in men affected by PD. ${ }^{20,28}$ When ED occurs in the course of $\mathrm{PD}$, besides having possible organic and structural causes such as those listed earlier, it can be caused by psychological problems linked to the presence of the disease (penile nodule, painful erection, penile deformity, etc). The mere fact of knowing that he has a disease affecting his genital organ tends to make the patient worry and be anxious, and this state can potentially interfere with the mechanism of penile erection. ${ }^{29}$ The psychological impact of the disease is not necessarily correlated with the degree of penile curvature; therefore, there may be strong distress in the presence of slight curvature and, vice versa, only a slight state of anxiety in the presence of marked penile curvature. ${ }^{30}$

Prevalence of psychological issues in patients with PD is very high and ranges from $77 \%$ to $81 \%$ of cases. ${ }^{31,32}$ Nelson et $\mathrm{al}^{33}$ found in their study a prevalence of clinically significant depression of $48 \%$ in patients affected by PD. The purpose of the present study is to evaluate the prevalence, psychological impact, and risk factors of ED in patients with PD.

\section{Patients and methods}

The study was conducted by carrying out a retrospective analysis of the clinical records of 309 patients affected by PD in its active stage, who visited and were studied at our andrology clinic between March 1, 2013, and October 31, 2015.

\section{Exclusion criteria}

To obtain a true overview of the presence and intensity of ED in PD and in order to achieve a correct evaluation of the most closely associated risk factors for ED as a symptom of PD, we excluded from the study all patients who were already affected by ED prior to the onset of PD, patients currently or previously treated with phosphodiesterase type 5 (PDE-5) inhibitors, and patients already cured or undergoing treatment for PD.

The medical history of the 309 patients was accurately reviewed, and any concurring diseases, possible risk factors, lifestyle habits (smoking, alcoholism, etc), and penile trauma were recorded; patients underwent physical examination, including measurement of weight and height to calculate their body mass index (BMI), and the following diagnostic tests: general blood tests and hormone assays, questionnaire for the assessment of erectile function (International Index of Erectile Function [IIEF], questions 1-5 and no 15, values $<26$ scores $=$ pathological $),{ }^{34}$ dynamic penile color Doppler ultrasonography (evaluation of plaque location, amount, and size; prostaglandin E-1 ( $\left.\mathrm{PGE}_{1}\right)$ injection at the dose of $10-20 \mathrm{mg}),{ }^{35,36}$ including imaging of the penis at maximum erection with photographic poses according to Kelâmi, ${ }^{37}$ goniometric measurement of penile curvature, psychosexual 
impact evaluation with Peyronie's Disease Questionnaire (PDQ, symptom bother domain score), ${ }^{38,39}$ evaluation of depression symptoms with the Patient Health Questionnaire (PHQ-9), ${ }^{40,41}$ and evaluation of the intensity of penile pain with the pain intensity numeric rating scale (score from 0 to 10$){ }^{42}$ To assess psychosexual impact, we used the PDQ symptom bother score, which consists of a series of questions (four scored items and two "yes/no" questions) addressing the patient's state of preoccupation and distress, on a scale that goes from 0 ("not at all bothered") to 4 ("extremely bothered"); the final score can therefore vary from 0 to $16 .^{38,39}$ Regarding the PHQ-9 questionnaire used to assess depressive symptoms, we considered the following classes of depression in relation to the scores obtained: minimal, score 1-4; mild, score 5-9; moderate, score 10-14; moderately severe, score 15-19; severe, score 20-27.40

Additionally, we carried out a study of the psychological impact related to the presence or absence of curvature and the degree of curvature. To this end, the patients were divided into four different groups, according to the following criteria: group $1=$ absence of curvature; group $2=$ curvature $<30^{\circ}$; group $3=$ curvature between $30^{\circ}$ and $60^{\circ}$; and group $4=$ curvature $>60^{\circ}$.

We analyzed the following potential risk factors of ED: coronary ischemia, dyslipidemia, diabetes mellitus, hypertension, obesity, benign prostatic hyperplasia, chronic prostatitis, autoimmune diseases, Dupuytren's contracture, androgen deficiency, previous penile trauma, and habitual cigarette smoking. We considered the following, by which some of the 309 patients were affected, autoimmune diseases: psoriasis (three cases), lichen sclerosus (balanitis xerotica obliterans, four cases), atopic dermatitis (one case), Hashimoto's thyroiditis (two cases), rheumatoid arthritis (three cases), ankylosing spondylitis (one case), and vitiligo (two cases). We considered obesity to be present when the BMI was 30 or higher $\left(\mathrm{kg} / \mathrm{m}^{2}\right){ }^{43}$

We considered hypogonadism to be present when serum testosterone levels were $<300 \mathrm{ng} / \mathrm{dL}(10.4 \mathrm{nmol} / \mathrm{L}){ }^{44}$

We therefore compared the clinical features of the group of patients with ED (group A) with those of patients without ED (group B), including a calculation of any risk factors (odds ratio [OR] calculation), first with a univariate analysis and subsequently with a multivariate analysis. To determine the most closely associated risk factors of ED, the ED-associated factors from the univariate analysis were used as independent variables for multivariate logistic regression analysis. Adjusted ORs (adj ORs) and 95\% confidence interval $(95 \% \mathrm{CI})$ for adj OR were calculated.
The categorical variables were statistically compared using the $\chi^{2}$ test, whereas for continuous variables the comparison was made using Student's $t$-test. A value of $P<0.05$ was considered statistically significant. The IBM SPSS 22.0 software (IBM Corporation, Armonk, NY) was used for statistical analysis.

\section{Statistical power of the sample}

A sample size of 302 cases was needed to detect an OR of 3.0 at $95 \%$ level of CI with a power of $90 \%$ (two tails) for a type I error rate of $\mathrm{a}=0.05$.

After the approval of the institutional (LILT) ethics committee, specific written informed consents were obtained from all 309 patients. Our study was conducted according to the Declaration of Helsinki of 1975, 1983, and subsequent revisions.

\section{Results}

We excluded from the present study 52 patients of which 19 had already been treated recently for PD, whereas the remaining 33 already suffered from ED before the onset of PD and had already been treated with PDE-5 inhibitors. Our study therefore included 309 patients affected by PD in its active stage, with a mean age of 50.6 years $( \pm 12.4 \mathrm{SD})$. ED was observed in 116 out of 309 patients, or $37.5 \%$ of cases; in all cases, ED had occurred in the course of PD. We then divided cases into two groups: group A (PD + ED), 116 cases and group $B$ (PD without ED), 193 cases. In three patients of group $\mathrm{B}$, in any case, the penis was unable to achieve penetration due to the presence of severe curvature $\left(70^{\circ}-75^{\circ}\right)$. Penile pain was present in 158 patients out of 309 (51.1\%), and the mean score on the pain intensity numeric rating scale was 4.7 \pm 2.1 SD. Penile curvature was present in 272 cases out of $309(88.02 \%)$, with a mean curvature of $\sim 30.4^{\circ} \pm 14.9^{\circ}$ SD. In six cases, even though there was no curvature, a deformation was present, which consisted of 12 cases in divots on the penile surface and in four cases in hourglass deformity.

Out of the total number of patients (group A + group B), a depressive state was observed in $62.4 \%$ (193 out of 309 ). With regard to the class of depression, in $84.97 \%$ (164 cases out of 193) it was minor depression (minimal + mild + moderate depression), whereas in $15.02 \%$ (29 cases out of 193) severe depression (moderately severe + severe depression) was present (Tables 1 and 2). A depressive state was more frequent in patients with PD + ED: 91.37\% (106 cases, group A) versus $45.07 \%$ ( 87 cases, group B; $P<0.0001$ ). Subsequently, stratifying the patients into various classes of depression (minimal, mild, moderate, moderately severe, and severe) and by carrying out this stratification even within the two groups, we saw that the higher level of depression (severe depression) is statistically 
Table I Clinical features of patients with PD according to the presence/absence of ED

\begin{tabular}{|c|c|c|c|c|}
\hline Clinical features & $\begin{array}{l}\text { All PD patients, } \\
\mathrm{N}=309\end{array}$ & $\begin{array}{l}\text { ED patients } \\
\text { (group A), } n=116\end{array}$ & $\begin{array}{l}\text { No ED patients } \\
\text { (group B), } n=193\end{array}$ & $\begin{array}{l}\text { Statistical analysis } \\
\text { (A versus B), } P \text {-value }\end{array}$ \\
\hline Age (years), mean $\pm S D$ & $50.613 \pm 12.413$ & $53.862 \pm 12.954$ & $48.735 \pm 11.693$ & 0.0005 (t-test) \\
\hline BMI $\left(\mathrm{kg} / \mathrm{m}^{2}\right)$, mean $\pm \mathrm{SD}$ & $24.76 \pm 2.77$ & $25.57 \pm 3.16$ & $24.27 \pm 2.38$ & $<0.000$ I ( $t$-test) \\
\hline Time from disease onset (months), mean \pm SD & $13.165 \pm 4.718$ & $|3.68| \pm 4.669$ & $12.854 \pm 4.733$ & 0.136 (t-test) \\
\hline Plaque volume $\left(\mathrm{cm}^{3}\right)$, mean $\pm S D$ & $0.801 \pm 0.718$ & $0.819 \pm 0.659$ & $0.790 \pm 0.752$ & 0.728 (t-test) \\
\hline Cases with calcification, n (\%) & $87(28.15)$ & $29(25.0)$ & $58(30.05)$ & $0.363\left(\chi^{2}\right.$ test $)$ \\
\hline Calcification volume $\left(\mathrm{cm}^{3}\right)$, mean $\pm S D$ & $0.152 \pm 0.435$ & $0.082 \pm 0.109$ & $0.187 \pm 0.526$ & 0.293 (t-test) \\
\hline Cases with penile curvature, $\mathrm{n}(\%)$ & $272(88.02)$ & $104(89.65)$ & $168(87.04)$ & $0.588\left(\chi^{2}\right.$ test $)$ \\
\hline Lateral, n (\%) & $127(46.69)$ & $50(48.07)$ & $76(45.23)$ & $0.707\left(\chi^{2}\right.$ test $)$ \\
\hline Dorsal, n (\%) & $86(31.6 I)$ & $31(29.8)$ & $57(33.92)$ & $0.507\left(\chi^{2}\right.$ test $)$ \\
\hline Ventral, n (\%) & $10(3.67)$ & $4(3.84)$ & $6(3.57)$ & $0.906\left(\chi^{2}\right.$ test $)$ \\
\hline Mixed dorsolateral, n (\%) & $4 \mathrm{I}(15.07)$ & $19(18.26)$ & $29(17.26)$ & 0.870 ( $\chi^{2}$ test $)$ \\
\hline Angle of penile curvature $\left({ }^{\circ}\right)$, mean \pm SD & $30.466^{\circ} \pm 14.969^{\circ}$ & $32.932^{\circ} \pm 16.628^{\circ}$ & $28.940^{\circ} \pm 13.674^{\circ}$ & 0.022 (t-test) \\
\hline Cases with penile pain, $\mathrm{n}(\%)$ & $158(5 \mid .13)$ & $56(48.27)$ & $102(52.84)$ & $0.48 \mathrm{I}\left(\chi^{2}\right.$ test $)$ \\
\hline Penile pain intensity (PI-NRS) score, mean \pm SD & $4.727 \pm 2.199$ & $5.2|4 \pm 2.34|$ & $4.460 \pm 2.080$ & 0.003 (t-test) \\
\hline Index of erectile function (IIEF) score, mean \pm SD & $24.469 \pm 3.262$ & $21.232 \pm 3.329$ & $26.4 \mid 4 \pm 0.553$ & $<0.000$ I (t-test) \\
\hline Presence of depression, $\mathrm{n}(\%)$ & $193(62.4)$ & $106(91.3)$ & $87(45.07)$ & $<0.000$ I $\left(\alpha^{2}\right.$ test $)$ \\
\hline Depression score (PHQ-9), mean \pm SD & $5.679 \pm 6.076$ & $8.353 \pm 5.918$ & $4.072 \pm 5.598$ & $<0.000$ I $(t$-test $)$ \\
\hline PDQ score (PD symptom bother score), mean \pm SD & $8.456 \pm 3.670$ & $9.758 \pm 3.006$ & $7.673 \pm 3.815$ & $<0.000$ I (t-test) \\
\hline
\end{tabular}

Notes: A value of $P<0.05$ was considered statistically significant; continuous variables were compared using the two-tailed Student's $t$-test whereas categorical variables were compared by use of the chi-square test.

Abbreviations: PD, Peyronie's disease; ED, erectile dysfunction; BMI, body mass index; SD, standard deviation; PI-NRS, pain intensity numeric rating scale; IIEF, International Index of Erectile Function; PHQ-9, Patient Health Questionnaire; PDQ, Peyronie's Disease Questionnaire.

Table 2 Assessment of depression and psychosexual impact in patients with PD

\begin{tabular}{|c|c|c|c|c|}
\hline Clinical features & $\begin{array}{l}\text { Total patients with } \\
\text { PD, } N=309\end{array}$ & $\begin{array}{l}\text { Cases with PD + ED } \\
\text { (group A), } n=116\end{array}$ & $\begin{array}{l}\text { Cases with PD without } \\
\text { ED (group B), } n=193\end{array}$ & $\begin{array}{l}\text { Statistical analysis } \\
\text { (A versus } B \text { ), } P \text {-value }\end{array}$ \\
\hline \multicolumn{5}{|l|}{ Evaluation of depressive symptoms with } \\
\hline \multicolumn{5}{|l|}{ PHQ-9 questionnaire } \\
\hline $\begin{array}{l}\text { Presence of depressive symptoms } \\
(\text { PHQ-9 score }>0), n(\%)\end{array}$ & $193(62.4)$ & $106(91.37)$ & $87(45.07)$ & $<0.000$ I $\left(\chi^{2}\right.$ test $)$ \\
\hline $\begin{array}{l}\text { Depression score (PHQ-9) in patients with } \\
\text { depression, mean } \pm \text { SD }\end{array}$ & $9.09 \pm 5.29$ & $9.14 \pm 5.57$ & $9.03 \pm 4.96$ & 0.889 (t-test) \\
\hline Minimal depression (score I-4), n (\%) & $36(18.65)$ & $13(|| .2)$ & $23(11.91)$ & $0.995\left(\chi^{2}\right.$ test $)$ \\
\hline Mild depression (score 5-9), n (\%) & $82(42.48)$ & $56(48.27)$ & $26(13.47)$ & $<0.000$ l ( $\chi^{2}$ test $)$ \\
\hline Moderate depression (score 10-14), n (\%) & $46(23.83)$ & $17(14.65)$ & $29(I 5.02)$ & $0.929\left(\chi^{2}\right.$ test $)$ \\
\hline $\begin{array}{l}\text { Moderately severe depression } \\
\text { (score 15-19), } \mathrm{n}(\%)\end{array}$ & $19(9.84)$ & II (9.48) & $8(4.14)$ & 0.084 ( $\chi^{2}$ test $)$ \\
\hline Severe depression (score 20-27), n (\%) & $10(5.18)$ & $9(7.75)$ & I (0.5I) & $0.0008\left(\chi^{2}\right.$ test $)$ \\
\hline $\begin{array}{l}\text { Evaluation of psychosexual impact with PDQ } \\
\text { (PD symptom bother score), mean } \pm \text { SD }\end{array}$ & $8.45 \pm 3.67$ & $9.758 \pm 3.006$ & $7.673 \pm 3.815$ & $<0.000 I$ ( $t$-test $)$ \\
\hline
\end{tabular}

Notes: A value of $P<0.05$ was considered statistically significant; continuous variables were compared using the two-tailed Student's $t$-test whereas categorical variables were compared by use of the chi-square test.

Abbreviations: PD, Peyronie's disease; ED, erectile dysfunction; PHQ-9, Patient Health Questionnaire; SD, standard deviation; PDQ, Peyronie's Disease Questionnaire.

more frequent in patients with $\mathrm{ED}$ (group A) compared with patients with no $\mathrm{ED}$ (group B): $7.7 \%$ versus $0.5 \%(P=0.0008)$; likewise, mild depression was more frequent in patients of group A compared with patients of group B: $48.2 \%$ versus $13.4 \%(P<0.0001)$. However, no statistically significant differences were found between the two groups in the remaining classes of depression (minimal, moderate, and moderately severe). Even the state of sexual bother, quantified with the PDQ symptom bother score, was qualitatively greater in group A than in group B $(9.7$ versus $7.6, P<0.0001)$.
Having then analyzed the characteristics of the psychological impact in relation to the presence or lack of curvature and the degree of curvature (Table 3), we found a greater prevalence and intensity of depressive symptoms in patients with penile curvature (65.4\%) PHQ-9 mean score $=5.6$ ) compared with those without curvature (40.5\%; PHQ-9 mean score $=2.8 ; P=0.0060$ and $P=0.0068$, respectively).

Stratifying the results, then, into the various curvature classes, we found that the prevalence and intensity of depression symptoms were significantly higher compared 


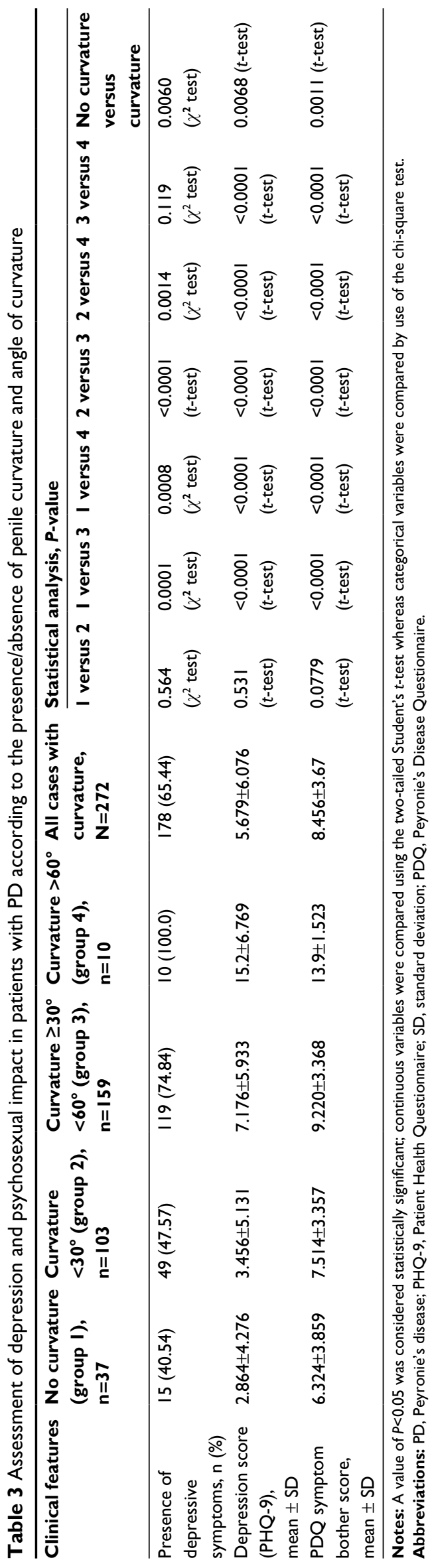

with patients with no curvature only in cases with an angle of $\geq 30^{\circ}$, whereas no statistically significant difference was observed between patients with no curvature and patients with a curvature $<30^{\circ}$ with regard to both prevalence $(P=0.564)$ and the intensity of symptoms of depression $(P=0.531$; Table 3). Analogously, with regard to the intensity of sexual distress, we recorded a greater intensity of symptom bother in cases with curvature (PDQ symptom bother score $=8.4$ ) compared with those without curvature (PDQ symptom bother score $=6.3 ; P=0.0011)$. After having analyzed the results stratified into various curvature classes, we found that the mean bother score on the PDQ was significantly higher compared with cases with no curvature only when the curvature angle was $\geq 30^{\circ}(P<0.0001)$, whereas we found no statistically significant difference between patients with curvature $<30^{\circ}$ and patients with no curvature ( $P=0.0779$; Table 3$)$.

Analyzing the results, we found that in patients with ED its origin was attributed to a psychogenic (non-organic) cause in 54 cases $(46.55 \%)$ and an organic vascular cause in 62 cases (53.44\%; Table 4); in four of the latter cases, PD onset had followed radical retropubic prostatectomy (bilateral nerve sparing) for prostatic adenocarcinoma. When ED was secondary to vascular cause, color Doppler ultrasound study allowed us to differentiate the following situations: pure venous occlusive dysfunction in 15 cases $(24.19 \%)$, inadequate cavernous arterial inflow in 41 cases $(66.12 \%)$, and inadequate cavernous arterial inflow associated with venous occlusive dysfunction in six cases $(9.67 \%)$.

Stratifying the 116 patients of group A by age (Table 4), we found that 20 of them $(17.24 \%)$ were $<40$ years of age, whereas the rest ( 96 patients, $82.75 \%$ ) were $>40$ years of age. In patients $<40$ years of age, ED was attributed to a psychogenic cause in $95 \%$ of cases (19 cases) and only in one case it was secondary to an organic cause (venous occlusive dysfunction; $P<0.0001$ ). In patients $\geq 40$ years of age, the prevailing cause of ED was, instead, organic $(63.5 \% ; 61$ cases out of a total of $96 ; P<0.0001$ ).

Furthermore, the following data were found to be statistically significant: mean BMI was higher in patients $\geq 40$ compared with patients whose age was $<40$ years ( 26.3 versus 21.9, $P<0.0001)$; mean time from $P D$ onset was greater in patients $\geq 40$ years of age ( 14.1 versus 11.6 months, $P=0.031$ ); incidence of penile curvature was higher in patients with age $\geq 40$ years ( 92.7 versus $75.0, P=0.032$ ); degree of penile curvature was higher in patients $\geq 40$ years of age $\left(35.6^{\circ}\right.$ versus $\left.16.6^{\circ}, P<0.0001\right)$; more frequent penile pain in patients $<40$ years of age ( $90 \%$ versus $39.5 \%, P<0.0001$ ); and mean IIEF score was significantly higher in patients who were $<40$ years of age (22.9 versus $20.8, P=0.013$ ). 
Table 4 Characteristics of PD + ED patients (group A) stratified by age

\begin{tabular}{|c|c|c|c|c|}
\hline Clinical features & $\begin{array}{l}\text { All patients with } \\
P D+E D, N=116\end{array}$ & Age $<40$ years, $n=20$ & Age $\geq 40$ years, $n=96$ & $\begin{array}{l}\text { Statistical analysis } \\
\text { (age }<40 \text { versus } \\
\text { age } \geq 40), P \text {-value }\end{array}$ \\
\hline Age (years), mean $\pm S D$ & $53.8 \pm 12.9$ & $30.3 \pm 3.5$ & $58.7 \pm 7.7$ & - \\
\hline $\mathrm{BMI}\left(\mathrm{kg} / \mathrm{m}^{2}\right)$, mean $\pm \mathrm{SD}$ & $25.57 \pm 3.16$ & $21.939 \pm 1.951$ & $26.334 \pm 2.827$ & $<0.000 \mathrm{I}(\mathrm{t}$-test $)$ \\
\hline $\begin{array}{l}\text { Time from disease onset (months), } \\
\text { mean } \pm \text { SD }\end{array}$ & $|3.68| \pm 4.669$ & 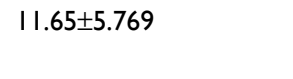 & | $4.104 \pm 4.322$ & 0.031 (t-test) \\
\hline Plaque volume $\left(\mathrm{cm}^{3}\right)$, mean $\pm S D$ & $0.819 \pm 0.659$ & $0.614 \pm 0.439$ & $0.862 \pm 0.690$ & 0.127 (t-test) \\
\hline Cases with calcification, $\mathrm{n}(\%)$ & $29(25.0)$ & $5(25.0)$ & $24(25.0)$ & $1.000\left(\chi^{2}\right.$ test $)$ \\
\hline Calcification volume $\left(\mathrm{cm}^{3}\right)$, mean $\pm S D$ & $0.082 \pm 0.109$ & $0.020 \pm 0.015$ & $0.095 \pm 0.116$ & 0.164 (t-test) \\
\hline Cases with penile curvature, n (\%) & $104(89.65)$ & $15(75.0)$ & $89(92.7)$ & $0.032\left(\chi^{2}\right.$ test $)$ \\
\hline Degree of penile curvature $\left(^{\circ}\right)$, mean $\pm S D$ & $32.932^{\circ} \pm 16.628^{\circ}$ & $16.66^{\circ} \pm 9.56^{\circ}$ & $35.67^{\circ} \pm 16.01^{\circ}$ & $<0.0001$ ( $t$-test $)$ \\
\hline Cases with penile pain, $\mathrm{n}(\%)$ & $56(48.27)$ & $18(90.0)$ & $38(39.58)$ & $<0.000$ I $\left(\chi^{2}\right.$ test $)$ \\
\hline $\begin{array}{l}\text { Penile pain intensity (PI-NRS) score, } \\
\text { mean } \pm \text { SD }\end{array}$ & $5.214 \pm 2.341$ & $5.944 \pm 2.208$ & $4.868 \pm 2.35$ & 0.108 (t-test) \\
\hline $\begin{array}{l}\text { Index of Erectile Function (IIEF) score, } \\
\text { mean } \pm S D\end{array}$ & $21.232 \pm 3.329$ & $22.9 \pm 2.989$ & $20.8 \pm 3.305$ & 0.013 (t-test) \\
\hline PDQ (PD symptom bother score), mean \pm SD & $9.758 \pm 3.006$ & $9.8 \pm 2.68$ & $9.75 \pm 3.08$ & 0.948 (t-test) \\
\hline Presence of depression, $\mathrm{n}(\%)$ & $106(91.3)$ & $18(90.0)$ & $88(91.6)$ & $0.682\left(\chi^{2}\right.$ test $)$ \\
\hline $\begin{array}{l}\text { Depression score (PHQ-9 questionnaire), } \\
\text { mean } \pm \text { SD }\end{array}$ & $8.353 \pm 5.918$ & $8.15 \pm 6.89$ & $8.39 \pm 5.73$ & 0.867 (t-test) \\
\hline $\begin{array}{l}\text { Psychogenic (nonorganic) cause } \\
\text { of ED, } n(\%)\end{array}$ & $54(46.5)$ & $19(95.0)$ & $35(36.45)$ & $<0.000$ I $\left(\chi^{2}\right.$ test $)$ \\
\hline Organic cause of ED, n (\%) & $62(53.4)$ & I (5.0) & $61(63.54)$ & $<0.000$ l $\left(\chi^{2}\right.$ test $)$ \\
\hline Veno-occlusive dysfunction, $\mathrm{n}(\%)$ & $15(24.19)$ & I (100.0) & $14(22.95)$ & - \\
\hline Arterial ED, $\mathrm{n}(\%)$ & $41(66.12)$ & $0(0)$ & $4 I(67.2 I)$ & - \\
\hline
\end{tabular}

Notes: A value of $P<0.05$ was considered statistically significant; continuous variables were compared using the two-tailed Student's $t$-test whereas categorical variables were compared by use of the chi-square test.

Abbreviations: PD, Peyronie's disease; ED, erectile dysfunction; BMI, body mass index; SD, standard deviation; PI-NRS, pain intensity numeric rating scale; IIEF, International Index of Erectile Function; PDQ, Peyronie's Disease Questionnaire; PHQ-9, Patient Health Questionnaire.

Furthermore, we found a greater incidence of association with certain risk factors in patients with PD + ED. Table 5 lists the potential risk factors, with their OR and statistical significance. Univariate analysis of the risk factors associated with ED, in patients with $\mathrm{PD}$, showed that, out of 12 variables, only eight showed a promise of influence: coronary artery disease, dyslipidemia, hypertension, obesity, benign prostatic hyperplasia, chronic prostatitis, autoimmune diseases, and cigarette smoking (Table 5).

Finally, multivariate logistic regression analysis of the ED risk versus the remaining eight variables was performed simultaneously, starting with a full model and removing nonsignificant variables one by one. After performing binary logistic regression analysis using these risk factors, the following were identified as independent risk factors of ED: benign prostatic hyperplasia (adj OR $=4.55 ; 95 \%$ CI: $1.738-11.912$ ), dyslipidemia (adj OR $=2.711 ; 95 \%$ CI: 1.284-5.724), chronic prostatitis (adj OR $=2.036 ; 95 \% \mathrm{CI}$ : $1.020-4.062$ ), obesity (adj OR $=3.138$; 95\% CI: 1.049 9.385), and autoimmune diseases ( $\operatorname{adj} \mathrm{OR}=3.187 ; 95 \% \mathrm{CI}$ : 1.070-9.495). Table 6 displays the adjusted multivariable logistic regression and the independent risk factors of ED.

\section{Discussion}

The results showed that ED was present in the course of PD in $37.5 \%$ of cases; other authors report a prevalence varying between $22 \%$ and $54 \% .1,13,45$

For the sake of completeness, since some authors have noted that, in certain cases, ED can precede the onset of PD (from $40.2 \%$ to $57.6 \%$ ), ${ }^{20-22}$ we considered all patients with $\mathrm{PD}+\mathrm{ED}$ (no 116 cases $=$ group $\mathrm{A}$ ) and those patients (no 33 cases) whom we excluded from the study because they were suffering from ED before the onset of PD. Then, in our outpatient experience 33 patients $(22.1 \%$ of the 149 cases with $\mathrm{PD}+\mathrm{ED})$ referred the presence of ED before the onset of PD.

In our study, ED was due to an organic cause more frequently (53.4\%), although only slightly so, than due to a psychogenic cause $(46.5 \%)$. When ED had an organic cause, this was attributable in all cases to a penile vascular disorder, even though in several cases the disorder was associated with comorbidities, such as diabetes, androgen deficiency, and dyslipidemia, which are certainly able to determine a disease progression. ${ }^{15,46}$ However, we never found androgen deficiency (low testosterone levels) to be the exclusive cause of ED; in fact, in the five cases where androgen deficiency 
Table 5 Univariate analysis of risk factors associated with ED in patients with PD

\begin{tabular}{|c|c|c|c|c|c|}
\hline Potential risk factors & Cases with ED (n= I |6), n (\%) & Cases without ED ( $n=193), n(\%)$ & OR & $95 \% \mathrm{Cl}$ & $P$ \\
\hline Coronary artery disease & $9(7.75)$ & $3(1.55)$ & 5.32 & $1.4 I-20.10$ & $0.013 *$ \\
\hline Dyslipidemia & $23(19.82)$ & $15(7.77)$ & 2.93 & $1.46-5.89$ & $0.002 *$ \\
\hline Diabetes & $13(1 \mid .2)$ & $10(5.18)$ & 2.3 & $0.97-5.45$ & 0.056 \\
\hline Hypertension & $31(26.72)$ & $33(17.09)$ & 1.76 & $1.01-3.08$ & $0.044^{*}$ \\
\hline Obesity & II (9.48) & $6(3.1)$ & 3.26 & $1.17-9.08$ & $0.023^{*}$ \\
\hline Benign prostatic hyperplasia & $15(12.9)$ & $7(3.6)$ & 3.94 & $1.55-9.99$ & $0.003 *$ \\
\hline Chronic prostatitis & $22(18.96)$ & $21(10.88)$ & 1.91 & $1.002-3.667$ & $0.049 *$ \\
\hline Autoimmune diseases & $10(8.62)$ & $6(3.1)$ & 2.94 & $1.03-8.31$ & $0.042 *$ \\
\hline Dupuytren's contracture & $4(3.44)$ & $5(2.59)$ & 1.34 & $0.35-5.1$ & 0.665 \\
\hline Low testosterone levels & $3(2.58)$ & $2(1.03)$ & 2.53 & $0.4 I-15.4$ & 0.312 \\
\hline Penile trauma & $8(6.89)$ & II (5.69) & 1.22 & $0.47-3.14$ & 0.671 \\
\hline Cigarette smoking & $14(12.06)$ & $10(5.1)$ & 2.51 & $1.07-5.85$ & $0.033 *$ \\
\hline
\end{tabular}

Note: *Statistical significance $(P<0.05)$ compared with non-ED group.

Abbreviations: ED, erectile dysfunction; $\mathrm{PD}$, Peyronie's disease; OR, odds ratio; $\mathrm{Cl}$, confidence interval.

Table 6 Multivariate analysis of risk factors associated with ED in patients with PD

\begin{tabular}{llll}
\hline Risk factors & Adjusted ORs & $\begin{array}{l}\text { 95\% Cl for } \\
\text { adjusted ORs }\end{array}$ & $P$ \\
\hline Benign prostatic hyperplasia & 4.550 & $1.738-11.912$ & $0.002^{*}$ \\
Dyslipidemia & 2.711 & $1.284-5.724$ & $0.009^{*}$ \\
Chronic prostatitis & 2.036 & $1.020-4.062$ & $0.044^{*}$ \\
Obesity & 3.138 & $1.049-9.385$ & $0.041^{*}$ \\
Autoimmune diseases & 3.187 & $1.070-9.495$ & $0.037^{*}$ \\
Coronary artery disease & 3.383 & $0.800-14.296$ & 0.097 \\
Cigarette smoking & 2.285 & $0.914-5.708$ & 0.077 \\
Hypertension & 1.245 & $0.671-2.310$ & 0.487 \\
\hline
\end{tabular}

Note: * Statistical significance $(P<0.05)$ compared with non-ED group.

Abbreviations: ED, erectile dysfunction; PD, Peyronie's disease; OR, odds ratio; $\mathrm{Cl}$, confidence interval.

was present, it was not associated with ED in two cases, whereas in three cases it was associated with ED which had a vascular cause (arteriogenic).

In patients $<40$ years, a psychogenic cause was found to prevail compared with an organic cause (95\% versus 5.0\%, $P<0.0001$ ); on the contrary, in patients with an age $\geq 40$ years the cause was significantly more likely to be organic than psychogenic ( $63.54 \%$ versus $36.45 \%, P=0.0003$ ). Contrary to the results of some authors, ${ }^{19,27}$ when ED had an organic cause, we found it to be more frequently an inadequate cavernous arterial inflow $(66.1 \%)$ than a venous occlusive dysfunction (24.1\%; $P<0.0001)$, and this concurs with the results of other authors. ${ }^{20-22,28}$

It is interesting to note that compared with the patients with no ED (group B), patients with ED (group A) had, on average: a higher age, by $\sim 5$ years ( 53.8 years versus 48.7 years, $P=0.0005)$; a higher BMI $\left(+1.3 \mathrm{~kg} / \mathrm{m}^{2}, P<0.0001\right)$; a higher degree of curvature $\left(+3.9^{\circ}, P=0.02\right)$; more intense penile pain, with a higher pain intensity numeric rating scale score $(+0.75, P=0.003)$; a higher incidence of depression $(91.3 \%$ versus $45.07 \%, P<0.0001)$, with a higher PHQ-9 score (+4.28, $P<0.0001$ ); and a greater intensity of sexual bother (PDQ symptom bother score: $+2.08, P<0.0001)$. In contrast to what other authors report, we found no correlation between plaque volume and the development, progression, and intensity of ED. ${ }^{47}$ As a matter of fact, comparing the mean volume of penile plaque in patients with $\mathrm{ED}\left(\right.$ group $\left.\mathrm{A}=0.819 \mathrm{~cm}^{3}\right)$ with the mean plaque volume in patients with no $\mathrm{ED}$ (group $\left.\mathrm{B}=0.790 \mathrm{~cm}^{3}\right)$, no statistically significant difference was observed $(P=0.728)$. On the contrary, singularly and in several cases we noted larger plaques in patients without ED (group B), and it is our conviction that plaque volume has no influence on the development of ED, except in the rarer "flail penis" cases. ${ }^{17,26}$

We believe, instead, that other risk factors play a truly decisive role in the onset and progression of ED in the course of PD. As already mentioned by other authors, very often psychological issues and depression develop in patients affected by PD. ${ }^{31-33}$

In $62.4 \%$ of cases (193 out of 309 cases) a depressive state was observed, and furthermore, $9.38 \%$ of patients (29 cases $=20$ cases with $\mathrm{ED}+$ nine cases without ED) were severely depressed. A depressive state was in any cases found to be more frequent in patients with PD + ED (91.37\% versus $45.07 \%, P<0.0001)$. Severe depression is statistically more frequent in patients with ED than in patients without ED (7.7\% versus $0.5 \%, P=0.0008$ ). Even sexual bother (PDQ symptom bother score) was more intense in group A compared with group B (9.7 versus 7.6, $P<0.0001)$.

The prevalence and intensity of depressive symptoms and the intensity of sexual bother were significantly higher compared with the cases with no curvature only when the curvature had an angle $\geq 30^{\circ}$ (and not for curvature $<30^{\circ}$ ). In effect, when penile curvature is absent or minimal, the psychological impact and state of preoccupation are quantitatively moderate. 
In-depth study of the clinical features of patients affected by $\mathrm{PD}+\mathrm{ED}$ and the subsequent multivariate analysis allowed us to identify the following independent risk factors for ED in patients with $\mathrm{PD}$ : dyslipidemia (adj OR $=2.711$ ), chronic prostatitis (adj OR =2.036), obesity (adj OR =3.138), benign prostatic hyperplasia (adj OR $=4.55$ ), and autoimmune diseases (adj OR =3.187). Although at first glance many of these risk factors may appear novel, actually these pathological conditions have already been proven to be risk factors for ED. ${ }^{48-53}$

\section{Conclusion}

ED is a frequent symptom in the course of PD. In males $<40$ years of age, the cause is almost always psychogenic, whereas in older men the cause is prevalently organic and vascular. Our experience showed us that when the cause of ED is vascular, in most cases it is due to an inadequate cavernous arterial inflow.

Patients affected by PD who present one of the following comorbidities have a greater likelihood of developing ED: dyslipidemia, obesity, chronic prostatitis, benign prostatic hyperplasia, and autoimmune diseases.

A depressive state is present in most patients affected by PD. Although results show that in patients with ED there is a greater prevalence of depressive symptoms than in patients without ED, we believe it is more alarming to note that $\sim 10 \%$ of patients with PD were found to be severely depressed.

The prevalence and intensity of depressive symptoms and the intensity of sexual distress are significantly greater than in cases with no curvature only when the curvature angle is greater.

Our study confirms that an integrated psychological support with medical treatment is needed in patients with PD.

\section{Acknowledgments}

We are especially grateful to Doctor Sandro Zicari (statistical expert, "Sapienza" University of Rome, Italy) for his contribution to the statistical analysis, in particular the multivariate analysis of risk factors of ED in patients with PD.

\section{Disclosure}

The authors report no conflicts of interest in this work.

\section{References}

1. Schwarzer U, Sommer F, Klotz T, Braun M, Reifenrath B, Engelmann U. The prevalence of Peyronie's disease: results of a large survey. $B J U$ Int. 2001;88(7):727-730.

2. Mulhall JP, Creech SD, Boorjian SA, et al. Subjective and objective analysis of the prevalence of Peyronie's disease in a population of men presenting for prostate cancer screening. J Urol. 2004;171(6 pt 1): 2350-2353.
3. Dibenedetti DB, Nguyen D, Zografos L, Ziemiecki R, Zhou X. A population-based study of Peyronie's disease: prevalence and treatment patterns in the United States. Adv Urol. 2011;2011:282503.

4. Diegelmann RF. Cellular and biochemical aspects of normal and abnormal wound healing: an overview. J Urol. 1997;157(1):298-302.

5. Somers KD, Dawson DM. Fibrin deposition in Peyronie's disease plaque. J Urol. 1997;157(1):311-315.

6. Dolmans GH, Werker PM, de Jong IJ, et al; LifeLines Cohort Study. WNT2 locus is involved in genetic susceptibility of Peyronie's disease. J Sex Med. 2012;9(5):1430-1434.

7. Van de Water L. Mechanisms by which fibrin and fibronectin appear in healing wounds: implications for Peyronie's disease. J Urol. 1997;157(1):306-310.

8. Gonzalez-Cadavid NF. Mechanisms of penile fibrosis. J Sex Med. 2009;6(suppl 3):353-362.

9. Paulis $\mathrm{G}$, Brancato T. Inflammatory mechanisms and oxidative stress in Peyronie's disease. Therapeutic "rationale" and related emerging treatment strategies. Inflamm Allergy Drug Targets. 2012;11(1):48-57.

10. Chilton CP, Castle WM, Westwood CA, Pryor JP. Factors associated in the aetiology of Peyronie's disease. Br J Urol. 1982;54(6):748-750.

11. Nugteren HM, Nijman JM, de Jong IJ, van Driel MF. The association between Peyronie's and Dupuytren's disease. Int J Impot Res. 2011;23(4): 142-145.

12. Lyles KW, Gold DT, Newton RA, et al. Peyronie's disease is associated with Paget's disease of bone. J Bone Miner Res. 1997;12(6):929-934.

13. Mulhall JP, Schiff J, Guhring P. An analysis of the natural history of Peyronie's disease. J Urol. 2006;175(6):2115-2118.

14. Sikka SC, Hellstrom WJ. Role of oxidative stress and antioxidants in Peyronie's disease. Int J Impot Res. 2002;14(5):353-360.

15. Garaffa G, Trost LW, Serefoglu EC, Ralph D, Hellstrom WJ. Understanding the course of Peyronie's disease. Int J Clin Pract. 2013;67(8):781-788.

16. Kadioglu A, Sanli O, Akman T, et al. Factors affecting the degree of penile deformity in Peyronie disease: an analysis of 1001 patients. JAndrol.2011; 32(5):502-508.

17. Pryor JP, Ralph DJ. Clinical presentations of Peyronie's disease. Int J Impot Res. 2002;14(5):414-417.

18. Paulis G, Cavallini G. Clinical evaluation of natural history of Peyronie's disease: our experience, old myths and new certainties. Inflamm Allergy Drug Targets. 2013;12(5):341-348.

19. Weidner W, Schroeder-Printzen I, Weiske WH, Vosshenrich R. Sexual dysfunction in Peyronie's disease: an analysis of 222 patients without previous local plaque therapy. J Urol. 1997;157(1):325-328.

20. Levine LA, Latchamsetty KC. Treatment of erectile dysfunction in patients with Peyronie's disease using sildenafil citrate. Int J Impot Res. $2002 ; 14(6): 478-482$.

21. Levine LA. Peyronie's disease and erectile dysfunction: current understanding and future direction. Indian J Urol. 2006;22(3):246-250.

22. Deveci S, Palese M, Parker M, Guhring P, Mulhall JP. Erectile function profiles in men with Peyronie's disease. J Urol. 2006;175(5):1807-1811.

23. Bjekic MD, Vlajinac HD, Sipetic SB, Marinkovic JM. Risk factors for Peyronie's disease: a case-control study. BJU Int. 2006;97(3):570-574.

24. Perimenis P, Athanasopoulos A, Gyftopoulos K, Katsenis G, Barbalias G. Peyronie's disease: epidemiology and clinical presentation of 134 cases. Int Urol Nephrol. 2001;32(4):691-694.

25. Kendirci M, Nowfar S, Gur S, Jabren GW, Sikka SC, Hellstrom WJ. The relationship between the type of penile abnormality and penile vascular status in patients with Peyronie's disease. J Urol. 2005;174(2):632-635.

26. Jalkut M, Gonzalez-Cadavid N, Rajfer J. Peyronie's disease: a review. Rev Urol. 2003;5(3):142-148.

27. Lopez JA, Jarow JP. Penile vascular evaluation of men with Peyronie's disease. J Urol. 1993;149(1):53-55.

28. Kadioğlu A, Tefekli A, Erol H, Cayan S, Kandirali E. Color Doppler ultrasound assessment of penile vascular system in men with Peyronie's disease. Int J Impot Res. 2000;12(5):263-267.

29. Chung E, Yan H, De Young L, Brock GB. Penile Doppler sonographic and clinical characteristics in Peyronie's disease and/or erectile dysfunction: an analysis of 1500 men with male sexual dysfunction. BJU Int. 2012;110(8):1201-1205. 
30. Rosen R, Catania J, Lue T, et al. Impact of Peyronie's disease on sexual and psychosocial functioning: qualitative findings in patients and controls. J Sex Med. 2008;5(8):1977-1984.

31. Smith JF, Walsh TJ, Conti SL, Turek P, Lue T. Risk factors for emotional and relationship problems in Peyronie's disease. J Sex Med. 2008;5(9):2179-2184.

32. Gelbard MK, Dorey F, James K. The natural history of Peyronie's disease. J Urol. 1990;144(6):1376-1379.

33. Nelson CJ, Diblasio C, Kendirci M, Hellstrom W, Guhring P, Mulhall JP. The chronology of depression and distress in men with Peyronie's disease. J Sex Med. 2008;5(8):1985-1990.

34. Rosen RC, Riley A, Wagner G, Osterloh IH, Kirkpatrick J, Mishra A. The international index of erectile function (IIEF): a multidimensional scale for assessment of erectile dysfunction. Urology. 1997;49(6):822-830.

35. Golijanin D, Singer E, Davis R, Bhatt S, Seftel A, Dogra V. Doppler evaluation of erectile dysfunction - part 1. Int J Impot Res. 2007;19(1):37-42.

36. Golijanin D, Singer E, Davis R, Bhatt S, Seftel A, Dogra V. Doppler evaluation of erectile dysfunction - part 2. Int J Impot Res. 2007;19(1):43-48.

37. Kelâmi A. Autophotography in evaluation of functional penile disorders. Urology. 1983;21(6):628-629.

38. Hellstrom WJ, Feldman R, Rosen RC, Smith T, Kaufman G, Tursi J. Bother and distress associated with Peyronie's disease: validation of the Peyronie's disease questionnaire. J Urol. 2013;190(2):627-634.

39. Hatzimouratidis K, Eardley I, Giuliano F, Moncada I, Salonia A; European Association of Urology [webpage on the Internet]. EAU Guidelines on Penile Curvature (Peyronie's Disease, p.3B.2); 2015. Available from: http://www.baus.org.uk/_userfiles/pages/files/professionals/sections/ EAU2015-Extended-Guidelines.pdf. Accessed June 15, 2016.

40. Kroenke K, Spitzer RL, Williams JB. The PHQ-9: validity of a brief depression severity measure. J Gen Intern Med. 2001;16(9):606-613.

41. Pastuszak AW, Badhiwala N, Lipshultz LI, Khera M. Depression is correlated with the psychological and physical aspects of sexual dysfunction in men. Int J Impot Res. 2013;25(5):194-199.
42. Farrar JT, Young JP Jr, LaMoreaux L, Werth JL, Poole RM. Clinical importance of changes in chronic pain intensity measured on an 11-point numerical pain rating scale. Pain. 2001;94(2):149-158.

43. Kataoka K. Indices of obesity derived from body weight and height. Nihon Rinsho. 1995;53(suppl):147-153.

44. Dandona P, Rosenberg MT. A practical guide to male hypogonadism in the primary care setting. Int J Clin Pract. 2010;64(6):682-696.

45. Kadioglu A, Tefekli A, Erol B, Oktar T, Tunc M, Tellaloglu S. A retrospective review of 307 men with Peyronie's disease. J Urol. 2002;168(3): 1075-1079.

46. Nam HJ, Park HJ, Park NC. Does testosterone deficiency exaggerate the clinical symptoms of Peyronie's disease? Int JUrol. 2011;18(11):796-800.

47. Chung E, De Young L, Brock GB. Penile duplex ultrasonography in men with Peyronie's disease: is it veno-occlusive dysfunction or poor cavernosal arterial inflow that contributes to erectile dysfunction? J Sex Med. 2011;8(12):3446-3451.

48. Tran CN, Shoskes DA. Sexual dysfunction in chronic prostatitis/chronic pelvic pain syndrome. World J Urol. 2013;31(4):741-746.

49. Rosen RC. Assessment of sexual dysfunction in patients with benign prostatic hyperplasia. BJU Int. 2006;97(suppl 2):29-33; discussion 44-45.

50. Ramírez R, Pedro-Botet J, García M, et al; Xarxa de Unitats de Lípids i Arteriosclerosi (XULA) Investigators Group. Erectile dysfunction and cardiovascular risk factors in a Mediterranean diet cohort. Intern MedJ. 2016;46(1):52-56

51. Corona G, Rastrelli G, Filippi S, Vignozzi L, Mannucci E, Maggi M. Erectile dysfunction and central obesity: an Italian perspective. Asian J Androl. 2014;16(4):581-591.

52. Pirildar T, Müezzinoğlu T, Pirildar S. Sexual function in ankylosing spondylitis: a study of 65 men. J Urol. 2004;171(4):1598-1600.

53. Hong P, Pope JE, Ouimet JM, Rullan E, Seibold JR. Erectile dysfunction associated with scleroderma: a case-control study of men with scleroderma and rheumatoid arthritis. J Rheumatol. 2004;31(3):508-513.
Research and Reports in Urology

\section{Publish your work in this journal}

Research and Reports in Urology is an international, peer-reviewed, open access journal publishing original research, reports, editorials, reviews and commentaries on all aspects of adult and pediatric urology in the clinic and laboratory including the following topics: Pathology, pathophysiology of urological disease; Investigation and treatment of

\section{Dovepress}

urological disease; Pharmacology of drugs used for the treatment of urological disease. The manuscript management system is completely online and includes a very quick and fair peer-review system, which is all easy to use. Visit http://www.dovepress.com/testimonials.php to read real quotes from published authors. 